Review

\title{
Mitochondria as Key Targets of Cardioprotection in Cardiac Ischemic Disease: Role of Thyroid Hormone Triiodothyronine
}

\author{
Francesca Forini $^{1, *}$, Giuseppina Nicolini ${ }^{1,2}$ and Giorgio Iervasi ${ }^{1}$ \\ 1 CNR Institute of Clinical Physiology, Via G. Moruzzi 1, Pisa 56124, Italy; \\ E-Mails: nicolini@ifc.cnr.it (G.N.); iervasi@ifc.cnr.it (G.I.) \\ 2 Tuscany Region G. Monasterio Foundation, Via G. Moruzzi 1, Pisa 56124, Italy \\ * Author to whom correspondence should be addressed; E-Mail: simona@ifc.cnr.it; \\ Tel.: +39-050-3152652.
}

Academic Editors: Jaime M. Ross and Giuseppe Coppotelli

Received: 21 January 2015 / Accepted: 12 March 2015 / Published: 19 March 2015

\begin{abstract}
Ischemic heart disease is the major cause of mortality and morbidity worldwide. Early reperfusion after acute myocardial ischemia has reduced short-term mortality, but it is also responsible for additional myocardial damage, which in the long run favors adverse cardiac remodeling and heart failure evolution. A growing body of experimental and clinical evidence show that the mitochondrion is an essential end effector of ischemia/ reperfusion injury and a major trigger of cell death in the acute ischemic phase (up to 48-72 $\mathrm{h}$ after the insult), the subacute phase (from $72 \mathrm{~h}$ to $7-10$ days) and chronic stage (from 10-14 days to one month after the insult). As such, in recent years scientific efforts have focused on mitochondria as a target for cardioprotective strategies in ischemic heart disease and cardiomyopathy. The present review discusses recent advances in this field, with special emphasis on the emerging role of the biologically active thyroid hormone triiodothyronine (T3).
\end{abstract}

Keywords: cardiac ischemia/reperfusion injury; low T3 syndrome; mitochondrial dysfunction; cardioprotection 


\section{Introduction}

Acute myocardial infarction (AMI) leading to ischemic heart disease is a major debilitating disease and important cause of death worldwide [1]. Deprivation of oxygen and nutrients following coronary occlusion is the primary cause of damage to the myocardium and its severity depends on the extent and duration of artery obstruction. Although timely, reperfusion effectively reduces short-term mortality, the reperfusion process itself yields additional injury, including cardiomyocyte dysfunction and death, which in the long run prompts adverse cardiac remodeling [1-3]. As a consequence, prevention or limitation of cardiac damage in the early stages of reperfusion is a crucial step in ameliorating patient prognosis.

Multiple lines of evidence show that mitochondrial functional impairments are critical determinants for myocyte loss during the acute ischemic stage, as well as for the progressive decline of surviving myocytes during the subacute and chronic stages [3-6]. Therefore, mitochondrial dysfunction is considered to be one of the major mechanisms in the pathogenesis of ischemia/reperfusion injury (IRI) and cardiomyopathy.

In spite of promising mitochondria-targeted therapeutic strategies emerging from experimental studies, very few have successfully completed clinical trials. As such, the mitochondrion is a potential untapped target for new therapies. Although ischemic pre-conditioning is a potent protective strategy first reported many decades ago [7], its utility in myocardial ischemia (MI) patients with an abrupt onset of disease undermines implementation of preconditioning in the clinical settings. Therefore, most modern approaches focus on the application of pharmacological or ischemic post-conditioning maneuvers to combat reperfusion injury and adverse cardiac remodeling [8].

Along this line, a growing body of clinical and experimental evidence shows that thyroid hormone (TH) supplementation may offer a novel option for cardiac diseases [9-12]. Indeed, 3,5,3'-triiodothyronine (T3), the biologically active form of TH, significantly declines after AMI both in animal models and in patients [13-15], with "low-T3 Syndrome" (low-T3S) being a strong independent prognostic predictor of death and major adverse cardiac events [16]. Consistently, treatment for low-T3S exerts cardioprotective effects in both humans and animal models [17-20].

Since the mitochondrion is a common effector of cardioprotective strategy and a main target of TH action [21-23], this review has a dual purpose: (1) to summarize the mitochondria-targeted noxious pathways and protective signaling that could be exploited to improve post-ischemic cardiac recovery and (2) to integrate classic and novel TH actions in a unified, mitochondria-centered picture that highlights how the crosstalk of TH with those molecular networks favors post-ischemic cardiomyocytes' survival.

\section{Triggers of Mitochondrial-Dependent Cardiomyocyte Death in Ischemia/Reperfusion}

\subsection{Mitochondrial Dysfunction in Ischemia/Reperfusion}

A wide spectrum of metabolic and ionic derangements occur in ischemia/reperfusion (I/R), culminating in mitochondrial impairment. Oxygen deprivation during ischemia arrests oxidative phosphorylation, decreasing intracellular ATP and favoring anaerobic glycolysis. The accumulation of lactic acid decreases the intracellular $\mathrm{pH}$. As a consequence, the $\mathrm{Na}^{+} / \mathrm{H}^{+}$antiporter is activated in an attempt to restore the $\mathrm{pH}$. The resulting accumulation of cytosolic sodium reverses the direction of 
the $\mathrm{Na}^{+} / \mathrm{Ca}^{2+}$ exchanger, leading to an increase in intracellular $\mathrm{Ca}^{2+}$ levels. The mitochondria act as a buffer for intracellular calcium, which ultimately causes calcium overload in the mitochondria [24,25]. This leads to an increase in ROS production from mitochondrial electron transfer complexes I and III, which consequently causes a decrease in anti-oxidant defenses [26-28]. The increased oxygen tension at the onset of reperfusion results in a greater burst of oxidative stress [29], which worsens mitochondrial dysfunction and alters membrane properties [5,30-32]. Damage to the mitochondrial outer membrane along with activation of the proapoptotic BCL-2 proteins leads to mitochondrial outer membrane permeabilization, release of cytochrome $c$, caspase activation, and apoptosis [33]. Massive oxidative stress can lead to a sudden increase in inner mitochondrial membrane permeability that is attributable to the opening of the so-called permeability transition pore (PTP). Opening of the PTP (PTPO) is accompanied by release of ROS and calcium [34,35]; this can propagate the damage to neighboring mitochondria and culminate in activation of calcium-dependent proteases (calpains) and lipases (cPLA2), inducing necrotic cell death [30,36]. The molecular nature of the PTP remains controversial, but current evidence implicates a matrix protein, Cyclophilin-D (Cyp-D), and two inner membrane proteins, adenine nucleotide translocase (ANT) and the phosphate carrier (PiC) [4,37-39].

An array of stress-responsive signaling pathways activated during early reoxygenation or in post-ischemic wound healing has been implicated in the regulation of these mitochondrial changes, and thus represents potential targets for therapeutic intervention.

\subsection{The p38 Mitogen-Activated Protein Kinase Intracellular Signaling}

A highly conserved component of myocyte stress-responsiveness in $I / R$ involves signaling through a family of serine-threonine kinase effectors known as p38 mitogen-activated protein kinase (p38MAPK). Four separate p38MAPK isoforms, including p38 $\alpha$, p38 $\beta$, p38 $\gamma$, and p38 identified. Each p38 isoform phosphorylates a diverse array of intracellular proteins including stress-responsive transcription factors [40].

This signaling cascade ultimately converges in mitochondria to enhance oxidative stress and mitochondrial-dependent cardiomyocyte death [41-43]. Among the pro-apoptotic targets activated by p38Mapk in $I / R$, the tumor suppressor protein p53 and Bax play key roles in determining both acute cell injury and post-ischemic adverse remodeling [44-46]. Also, it has been demonstrated that p38 MAPK plays a causative role in the inhibition of the anti-apoptotic Bcl-2 protein [47]. Accordingly, inhibitors of p38 signaling have been shown to confer protection from IRI [48].

\section{TH Inhibits p38MAPK under Stress Conditions}

TH exhibits a prominent role in the regulation of p38MAPK. In the post-ischemic rat brain, thyroxine, T4, treatment was protective through its p38-targeted anti-apoptotic and anti-inflammatory mechanism [49]. In Langendorff-perfused rat heart models of I/R, long-term T4 pretreatment or acute T3 administration markedly improved post-ischemic recovery of left ventricular performance while reducing cardiomyocyte death markers and blunting the activation of p38MAPK [50,51]. As suggested by a subsequent study, this effect was mediated at least in part by the thyroid hormone receptor $\alpha 1$ (TR $\alpha 1$ ) [52]. Indeed, in a mouse model of AMI, pharmacological inhibition of TR $\alpha 1$ further depressed post-ischemic cardiac function and was accompanied by marked activation of p38MAPK [52]. 


\subsection{Tumor Suppressor Protein p53}

\subsection{1. p53 and Cardiomyocyte Death: Direct Action}

Tumor suppressor protein p53 accumulates in the myocardium after myocardial infarction, and plays an important role in the progression to heart failure. It is well established that p53 can trigger apoptosis through the mitochondrial pathway [53]. For example, it can trans-activate Bax, the pro-apoptotic member of the BCL-2 family that translocates from the cytosol to mitochondria, causing the release of apoptotic proteins [54,55]. Besides its classic role, a broader role in organ homeostasis is just beginning to be understood. It has recently been reported that in response to oxidative stress, p530 accumulates in the mitochondrial matrix and triggers mitochondrial PTPO and necrosis by physical interaction with the PTP regulator Cyclophilin D (Cyp-D) [56]. p53 also plays a critical role in other important processes that regulate mitochondrial integrity but are impaired in I/R, such as mitochondrial morphology and mitophagy [57,58].

\subsection{2. p53 Regulation of Mitochondrial Morphology}

Mitochondria change their morphology by undergoing either fusion or fission, resulting in either elongated, tubular, interconnected mitochondrial networks or fragmented, discontinuous mitochondria, respectively $[59,60]$. These two opposing processes are regulated by the mitochondrial fusion proteins: mitofusin (Mfn) 1, Mfn2, and optic atrophy protein 1(OPA1); and the mitochondrial fission proteins: dynamin-related protein 1 (Drp1) and human mitochondrial fission protein 1 (hFis1). The fine balance between mitochondrial fusion and fission within a cell may be upset by a variety of factors, including oxidative stress [61] and ischemia [34,62], which can predispose the cell to apoptosis and mitochondrial PTPO [63], critical mediators of IRI.

p53 affects the mitochondrial dynamic by two opposite mechanisms that disrupt the equilibrium between fission and fusion, promoting cell death. In one way, p53 may upregulate Drp1 with consequent activation of excessive mitochondrial fission [64]. Drp1, in turn, stabilizes p53 in the mitochondria to trigger necrosis [65]. On the other hand, p53 may promote indirect, Bax-mediated, excessive mitochondrial fusion leading to cell necrosis as well [66].

\subsection{3. p53 Effect on Mitophagy}

In response to stress, cells have developed mitophagy, a defense mechanism that involves selective sequestration and subsequent degradation of the dysfunctional mitochondrion [67]. In I/R, mitophagy functions as an early cardioprotective response, favoring the removal of damaged mitochondria before they can cause activation of cell death [58]. The E3 ubiquitin ligase Parkin was recently discovered to play an important role in targeting damaged mitochondria for removal via autophagy in cardiomyocytes [58]. The proposed mechanism involves Mfn2 activation and Parkin recruitment from the cytosol to depolarized mitochondria [68]. Interestingly, another report showed Parkin localization to depolarized mitochondria even in the absence of Mfn2, which could indicate the presence of alternative mechanisms for Parkin translocation [69]. 
In the mouse heart, p53 cytosolic accumulation induces mitochondrial dysfunction by binding to Parkin and disturbing its translocation to damaged mitochondria and their subsequent clearance by mitophagy [70]. On the contrary, p53 knock-down preserved mitophagic flux under ischemia without a change in cardiac tissue ATP content [71]. Analysis of autophagic mediators acting downstream of p53 revealed that the TP53-induced glycolysis and apoptosis regulator (TIGAR) mediated the inhibition of myocyte mitophagy responsible for impairment of mitochondrial integrity and subsequent apoptosis, and this process is closely involved in p53-dependent ventricular remodeling after myocardial infarction [71].

\section{Promoters of Mitochondria-Mediated Cardioprotection in Ischemia/Reperfusion}

\subsection{The Reperfusion Injury Salvage Pathway}

A central biochemical pathway involved in cytoprotection is the phosphoinositide 3-kinase (PI3K) pathway, also known as the reperfusion injury salvage kinase (RISK) pathway. This pathway consists of a tyrosine kinase receptor (RTK) whose activation results in the recruitment of PI3K. Next, PI3K activates Akt, which in turn phosphorylates downstream kinases [72]. Regarding the heart, the literature on Akt is extensive [73] and has largely established Akt as a key pro-survival kinase in normal cardiac homeostasis and in response to injury. Classically, Akt activation promotes survival via inhibition of pro-apoptotic Bcl-2 family proteins Bax and Bad, limiting mitochondrial outer membrane (OMM) permeabilization and thereby blocking release of cytochrome $c$ and caspase-mediated apoptosis. The RISK pathway is also implicated in PTP regulation and preservation of mitochondrial membrane potential $(\Delta \Psi \mathrm{m})$ [74]. The glycogen synthase kinase 3- $\beta$ (GSK-3 $\beta$ ) is a key downstream target of Akt and is inactive when phosphorylated. Thus, GSK-3 $\beta$ phosphorylation by Akt or other upstream mediators results in inhibition of GSK-3 $\beta$-activated targets. For example, inactivation of GSK-3 $\beta$ by Akt reduces mitochondrial Bax recruitment [75] as well as PTPO [76,77]. Enhancement of p53 activity by GSK-3 $\beta$ and GSK-3 $\beta$ interaction with CypD may have a role in mPTP opening $[78,79]$. The use of GSK-3 $\beta$ inhibitors in the post-ischemic setting is hampered by the side effect of inhibiting the physiological function of GSK-3 $\beta$ [80]. To overcome this limitation, selective inhibition of GSK-3 $\beta$ mitochondria uptake has been reported as a promising and novel approach to cardioprotection from lethal reperfusion injury [81].

The recruitment of the RISK pathway also induces phosphorylation-dependent activation of the endothelial nitric oxide synthase (eNOS), which is expected to block PTPO through its release of nitric oxide (NO) [82]. In turn, NO triggers the opening of the mitochondrial ATP-dependent potassium channels (mitoKATP) [83], a cardioprotective process that has been causally related to post-conditioning [84]. Furthermore, an increase in NO availability may enhance mitochondrial protein $S$-nitrosylation (SNO) and promote cardioprotection $[85,86]$. Finally, the RISK pathway has also been shown to confer cardioprotection against IRI by modulating Mfn1-dependent mitochondrial morphology [86,87]. 
Role of Thyroid Hormone in the Activation of Reperfusion Injury Salvage Pathway

THs are critically involved in the activation of the RISK pathways in both physiological and stress conditions. Rapid T3-mediated activation of PI3K by cytosolic TR $\alpha 1$, and subsequent activation of the Akt-mTOR signaling pathway, has been proposed as one of the mechanisms by which TH regulates physiological cardiac growth [88]. T3 administration can prevent serum starvation-induced neonatal cardiomyocyte apoptosis via Akt [89]. In vivo T4 treatment has been shown to cause phosphorylation of Akt and downstream signaling targets such as GSK-3 $\beta$ and mTOR in rat heart ventricles [90]. The Akt-mediated cardioprotective action of $\mathrm{TH}$ was confirmed in an experimental model of rat myocardial ischemia, where early short-term treatment of T3 reduced myocytes apoptosis through activation of Akt [19]. In a recent study, TH was found to have a dose-dependent effect on Akt phosphorylation, which may be of physiological relevance [91]. Mild activation of Akt caused by the replacement dose of $\mathrm{TH}$ resulted in favorable effects, while further induction of Akt signaling by higher doses of $\mathrm{TH}$ was accompanied by increased mortality and activation of extracellular signal-regulated kinases (ERK), some of the most well-studied kinases in relation to pathological remodeling [92]. This study may be of important therapeutic relevance because it shows that $\mathrm{TH}$ replacement therapy may be sufficient to restore cardiac function, while excessive TH doses may be detrimental rather than beneficial.

\subsection{Inhibition of p53 Signaling}

Given the detrimental effects of p53 in the myocardial IRI, this molecule may be proposed as a central hub in stress-induced apoptosis and necrosis instigated in mitochondria and may act as a novel therapeutic target [93].

\section{Role of Thyroid Hormone in the Inhibition of p53 Signaling}

Thyroid hormone is a critical regulator of p53 activity. A p53-centered anti-apoptotic action of TH has been well characterized in tumor cells $[94,95]$. In a rat model of post-ischemic acute stroke, TH treatment reduced cerebral infarction while limiting cell death through modulation of the p53 targets Bax and BCl2 [49]. On the other hand, p53 is able to hamper TH signaling. Early studies showed that the physical interaction of thyroid hormone receptors (TRs) with p53 inhibited the binding of TRs to the TH-responsive elements (TREs) in a concentration-dependent manner and that this interaction negatively regulated the TRs' signaling pathways [96,97]. Although these data collectively suggest that the cross-talk between p53 and TH may play an important role in physiological and pathological conditions, its role in cardiac disease evolution is only beginning to be explored. A recent paper reported a critical role for $\mathrm{TH}$ in inhibiting the p53-dependent activation of mitochondrial-mediated cell death in a model of cardiac I/R [98]. In this study, the low-T3S following the ischemic insult was accompanied by an up-regulation of p53 and activation of its downstream events, such as Bax induction and mitochondrial impairment. Early T3 administration at near-physiological dose improved the recovery of post-ischemic cardiac performance. At the molecular level, T3 blunted p53 and Bax up-regulation in the area at risk (AAR), thus preserving mitochondrial function and decreasing apoptosis and necrosis extent in the AAR [98]. Similarly, in cardiomyocytes exposed to oxidative 
stress, T3 treatment reduced cell death, preserved mitochondrial biogenesis and membrane potential, and limited p53 upregulation [98,99].

\subsection{Targeting Mitochondrial Oxidative Stress}

In accordance with a role for mitochondrial dysfunction and ROS production in the pathogenesis of heart disease, it has been shown that targeted mitochondrial ROS scavenging reduces remodeling whereas non-targeted ROS treatment has no effect [32]. This is in agreement with the lack of benefit provided by non-targeted anti-oxidants in the clinical arena [100,101], and supports the general concept of compartmentalized signaling. This concept implies close vicinity of signaling molecules to provide local control over second messengers; in this regard, targeted ROS scavenging, which accumulates manifold at the microdomains of ROS formation in mitochondria, might be more efficient in the specific targeting of cellular ROS signaling. One relevant paper suggests that mitochondria-targeted Bendavia may be extremely effective in preventing reperfusion-induced damage to cardiac mitochondria [102]. Mitoquinone (mitoQ), a coenzyme Q analog, easily crosses phospholipid bilayers and is driven to concentrate within mitochondria by the large electrochemical membrane potential. The respiratory chain reduces mitoQ to its active ubiquinol antioxidant form to limit myocardial I/R injury [103]. The SS-31 (Szeto-Schiller) peptide is also of interest since it is cell-permeable and specifically targeted to inner mitochondrial membranes based on its residue sequence, with an anti-oxidant dimethyltyrosine moiety. SS-31 has been shown to be taken up by the heart in an ex vivo reperfusion system and was protective against I/R injury [104]. The peptides SS-02 and SS-31 were also protective against cardiac I/R injury when added during reperfusion [105].

Role of Thyroid Hormone in the Inhibition of Mitochondrial Oxidative Stress

It has recently been shown that $\mathrm{TH}$ has a mitochondria-targeted antioxidant protective effect under in vitro stress conditions and after myocardial infarction in vivo $[98,99,106]$. In cultured cardiomyocytes, T3 treatment decreased oxidative stress-induced cell death while maintaining mitochondrial function [99]. These effects were prevented by inhibitors of mitoKATP channel opening, suggesting that activation of the mitoKATP channel in rescued mitochondria is an important protective mechanism elicited by T3 against oxidative stress-mediated cell death [99]. In a post-ischemic HF model, TH administration during the post-infarction period leads to normalization of the myocardial performance index, reduction of ROS level, and stimulation of cytosolic and mitochondrial anti-oxidant defenses [106]. In an experimental AMI model, T3 supplementation reduced mitochondrial superoxide production and limited inner mitochondrial membrane depolarization, thus improving mitochondrial function and cell viability [99].

\subsection{Inhibition of Mitochondrial Permeability Transition Pore Opening}

Since the initial reports on the existence of mitochondrial cyclophilin in the late 1980s, a vast majority of studies have recognized the crucial role of Cyp-D in PTP regulation. In animal models, inhibition of Cyp-D by either pharmacologic targeting [107,108], genetic ablation [109,110], or RNA interference [111], provides strong protection from both reperfusion injury and post ischemic HF. 
Although chronic pharmacological inhibition of CypD has been shown to cause metabolic reprogramming and worsening of pressure-induced HF [112], its acute inhibition to attenuate lethal IR injury holds great promise for reducing myocardial infarct size in humans [8,113]. Besides Cyp-D, several physiological regulators of $\mathrm{mPTP}$ function may be exploited to confer cardioprotection from I/R injury.

One important class of endogenous transducers of cell stress signals are the signal transducer and activator of transcription (STAT) proteins. Several STAT isoforms are expressed in the heart; among them, STAT3 is involved in the reduction of post-ischemic myocardial injury [114]. The infarct size reduction by ischemic post-conditioning is also attenuated in STAT3-KO mice [115]. STAT3 has been localized in mitochondria, where it contributes to cardioprotection by stimulating respiration and inhibiting the $\mathrm{Ca}^{2+}$-induced mitochondrial PTPO [116].

Nitric oxide (NO) is another important signaling molecule that has been shown to reduce myocardial injury in a number of ischemia/reperfusion models. For example, brief periods of NO breathing reduced myocardial injury from ischemia/reperfusion in mice and pigs [117-119]. A critical process during NO-induced cardioprotection is to prevent mitochondrial PTPO potentially via targeting of the ANT component of the pore-forming complex [120].

Hypoxia inducible factor $1 \alpha(\mathrm{HIF}-1 \alpha)$ is an oxygen-sensitive transcription factor that enables aerobic organisms to adapt to hypoxia. This is achieved through the transcriptional activation of up to 200 genes, many of which are critical to cell survival [121]. Under normoxic conditions, the hydroxylation of HIF-1 $\alpha$ by prolyl hydroxylase domain-containing (PHD) enzymes targets it for proteosomal degradation. However, under hypoxic conditions, PHD activity is inhibited, thereby allowing HIF-1 $\alpha$ to accumulate and translocate to the nucleus, where it binds to the hypoxia-responsive element sequences of target gene promoters. Experimental studies suggest that stabilization of HIF-1 $\alpha$ may protect the heart against the detrimental effects of acute I/R injury [121].

\section{Role of TH in the Inhibition of Permeability Transition Pore Opening}

The mechanisms underlying the myocyte-directed protective effect of HIF are not completely clear. A recent paper showed that HIF-1 $\alpha$ stabilization, by either a pharmacological or genetic approach, protected the heart against acute IRI by inhibiting mitochondrial PTPO and decreasing mitochondrial oxidative stress [122]. Accordingly, T3 replacement has been shown to induce HIF-1 $\alpha$ stabilization in a post-ischemic HF model, which was related to better preserved mitochondrial activity and cardiac performance [99].

\subsection{Mitochondrial Biogenesis}

Mitochondrial biogenesis has emerged as an important point in the multi-site control of mitochondrial function and a putative target for therapeutic intervention against cardiac IRI [123,124]. Mitochondrial biogenesis includes regulation of mitochondrial protein expression, their assembly within the mitochondrial network, and replication of mitochondrial DNA (mtDNA). Of the 1500 proteins representing the mitochondrial proteome, mtDNA provides 13 subunits of the oxidative phosphorylation system together with ribosomal and transfer RNAs; whereas more than $98 \%$ of the mitochondrial protein requirement is encoded by the nuclear genome [125]. Hence, a spatial and temporal coordination of nuclear and mitochondrial genomes is necessary to ensure that all mitochondrial components are 
available for correct assembly. The master regulator of the process is the nuclear-encoded peroxisome proliferator-activated receptor- $\gamma$ coactivator- $1 \alpha$ (PGC1- $\alpha$ ). PGC-1 $\alpha$ lacks DNA-binding activity but interacts and coactivates numerous transcription factors driving mitochondrial biogenesis, energy metabolism, fatty acid oxidation, and antioxidant activity [126]. In particular, PGC-1 $\alpha$ activates nuclear transcription factors (NTFs) leading to upregulation of nuclear-encoded proteins. Nuclear-encoded proteins are imported into mitochondria through the outer-membrane (TOM) or inner-membrane (TIM) translocase transport machinery. Finally, nuclear- and mitochondrial-encoded subunits of the respiratory chain are assembled [127]. A downregulation of the entire pathway of mitochondrial biogenesis was reported both in AMI and in HF evolution [128,129]. Reduced PGC-1 $\alpha$ activity and gene expression have been observed in several experimental models of pathologic cardiac hypertrophy, and HF $[130,131]$ and has been involved in the pathogenesis of human heart disease [132]. It has been shown that in the heart, pathological stressors such as ischemia are associated with a downregulation of mitochondrial biogenesis via PGC-1 $\alpha$ activity [133], and that impairment of the PGC-1 $\alpha$-mediated mitochondrial biogenesis increased heart vulnerability to IRI [134]. Accordingly, upregulation of the PGC-1 $\alpha$ pathway confers protection against simulated I/R in cardiomyoblast cells [135]. Moreover, the induction of PGC-1 $\alpha$ protein upregulates a broad spectrum of ROS detoxification systems, such as superoxide dismutase 2 (SOD2) and glutathione peroxidase-1 [136]. Hence, a putative mechanism whereby the mitochondrial biogenesis program may additionally augment tolerance to cardiac ischemia is via ROS detoxification.

During mitochondrial biogenesis, the coordinated transcription and replication of the mitochondrial genome is carried out via the nuclear-encoded mitochondrial transcription factor A (mtTFA), a downstream effector of PGC1- $\alpha$ signaling. It has long been recognized that post-ischemic adverse remodeling is frequently associated with qualitative and quantitative defects in mtDNA [137-139], and that a decline in mitochondrial function and mtDNA copy number play a major role in the development of post-ischemic heart disease [31,140]. In accordance, targeted disruption of mtTFA specifically within cardiac tissue resulted in a significant decrease in electron transport capacity, spontaneous cardiomyopathy, and cardiac disease [141,142]. Conversely, increasing the expression of mtTFA within cardiac tissue offered protection from adverse remodeling induced by myocardial infarction [143].

Given the causative role of mitochondrial dis-homeostasis in adverse cardiac remodeling, understanding the stimuli, signals, and transducers that govern mitochondrial biogenesis pathways may have critical significance in the treatment of ischemic cardiovascular disorders. In the last few years, the $\mathrm{NAD}^{+}$-dependent protein deacetylase sirtuin 1 (SIRT1) has emerged as an important regulator of mitochondrial biogenesis [144,145]. Besides its epigenetic role in silencing of transcription by heterochromatin formation through histones modification, SIRT1 influences the activity of PGC-1 $\alpha$ through a functional protein-protein interaction [146]. SIRT1 activation of PGC-1 $\alpha$ enhances mitochondrial biogenesis, optimizes mitochondrial surface/volume ratio to reduce ROS production, and mounts an antioxidant defense [146,147]. Several lines of evidence show that SIRT1 has pivotal roles in cardiovascular function. Transgenic mice that overexpress SIRT1 in the heart are resistant to oxidative stress-related cardiac hypertrophy and ischemia/reperfusion injury $[148,149]$. In addition, the putative SIRT1 activator, resveratrol, a recognized mediator of mitochondrial biogenesis, can 
ameliorate heart ischemia or reperfusion injury, improve vascular functions, and ameliorate Ang II-induced cardiac remodeling [150,151].

Thyroid Hormone Is Key Regulator of Mitochondrial Biogenesis

Thyroid hormone plays a crucial role in regulation of mitochondrial biogenesis in both physiological and pathological conditions [24]. PGC-1 $\alpha$ is rapidly and strongly induced by TH. PGC-1 $\alpha$ expression and protein levels are increased $6 \mathrm{~h}$ after administration of T3, and this action is mediated by a $\mathrm{TH}$ responsive element (TRE) in the promoter [152-154]. In a rat model of post-ischemic HF, a low-T3S correlated with PGC-1 $\alpha$ and mtTFA downregulation, which corresponded to decreased mitochondrial function in the border zone; T3 replacement rescued myocardial contractility and hemodynamic parameters, while maintaining the expression of PGC-1 $\alpha$ and mtTFA and mitochondrial function [99]. Since the PGC-1 $\alpha$ pathway is downregulated by p53 activation under oxidative stress conditions, the inhibitory role of T3 on p53 expression may be part of an additional and indirect mechanism by which TH controls PGC1- $\alpha$ levels in the post-cardiac ischemia setting [155].

The reduced PGC1- $\alpha$ level in the post-ischemic low-T3S is consistent with the activation of a fetal metabolic pathway observed in cardiomyopathy that is characterized by a preference for glucose over fat as a substrate for oxidative phosphorylation. Although such changes lower the oxygen consumed per ATP produced, the yield of ATP per substrate also decreases. Such inefficient metabolism lowers ATP and phosphocreatine levels and decreases metabolic reserve and flexibility, leading to pump dysfunction [156,157]. Therefore, T3 supplementation in low T3 post-ischemic cardiomyopathy may favor the normal mitochondrial homeostasis and metabolic flexibility of the heart, preventing adverse cardiac remodeling and HF evolution.

Thyroid-stimulated mitochondrial biogenesis appears to be mediated via specific TRs located in both the nuclear and mitochondrial compartments [21,22]. Wrutniak-Cabello et al. [158] reported the discovery in mitochondria of two $N$-terminally truncated forms of the T3 nuclear receptor, TR $\alpha$, with molecular weights of 43 and $28 \mathrm{kDa}$, respectively. While the function of p28 remains unknown, p43 is a T3-dependent transcription factor of the mitochondrial genome, acting through dimeric complexes involving at least two other truncated forms of nuclear receptors, mitochondria retinoid $\mathrm{X}$ receptor (mtRXR) and mitochondrial peroxisome proliferator-activated receptor (mtPPAR); p43 activation by T3 stimulates mitochondrial protein synthesis, respiratory chain activity, and mitochondriogenesis [23]. Similarly, Saelim et al. [159] reported that T3 bound TH truncated receptor isoforms (TRs) target mitochondria where they modulate inositol 1,4,5 trisphosphate (IP3)-mediated $\mathrm{Ca}^{2+}$ signaling [160] to inhibit apoptotic potency.

\subsection{MicroRNAs}

MicroRNAs (miRNAs) are a subset of regulatory molecules involved in several cellular processes of cardiac remodeling and heart failure (HF) [161-164], and have become an intriguing target for therapeutic interventions [165]. In response to diverse cardiac stresses such as myocardial $I / R$, miRNAs are reported to be up- or downregulated [166-169]. Some of them have recently attracted attention as regulators of mitochondrial function and mitochondrial cell death signaling in both myocardial I/R and in vitro models of oxidative stress [170-174]. 
Role of Thyroid Hormone in the Regulation of Cardioprotective miRNA

The miR-30 family members are abundantly expressed in the mature heart, but they are significantly downregulated in experimental I/R and in vitro after oxidative stress [174-176]. Li et al. [173] report that miR-30 family members are able to regulate apoptosis by targeting the mitochondrial fission machinery. In exploring the underlying molecular mechanism, they identified that miR-30 family members inhibited mitochondrial fission by suppressing the expression of p53 and its downstream target, dynamin-related protein 1 (Drp1) [174]. Therefore, maintenance of miR-30 levels in I/R may be regarded as cardioprotective. In a rat model of I/R, early short-term T3 supplementation at near-physiological dose maintained the post-ischemic level of miR-30a, leading to a depression of p53 and inhibition of p53 detrimental effects on mitochondria [98]. In turn, p53 is responsible for the post-ischemic inhibition of miR-499, another highly expressed cardiac miRNA with a key role in the regulation of mitochondrial dynamic [64]. MiR-499 levels are reduced in experimental ischemia as well as in anoxic cardiomyocytes, and this reduction is causally linked to apoptosis and the severity of myocardial infarction and cardiac dysfunction induced by I/R [64]. MiR-499 inhibits cardiomyocyte apoptosis through its suppression of calcineurin-mediated dephosphorylation of Drp1, thereby decreasing Drp1 accumulation in mitochondria and Drp1-mediated activation of the mitochondrial fission program [64].

\section{Closing Remarks and Conclusions}

In the last three decades, several biochemical pathways conveying $I / R$ deleterious effects to the mitochondria have been characterized. In parallel, several endogenous protective molecules that enhance mitochondrial survival have been identified and, consequently, prevent progression to HF. As depicted in Figure 1, TH acts on both noxious and beneficial pathways to induce cardioprotection from IRI. Therefore, treatment of post-ischemic low-T3S appears to be a promising modality for reducing mitochondrial-driven IRI and preventing progression to HF. However, from a translational point of view, there are still some unsolved issues regarding the dose and timing of $\mathrm{TH}$ administration after AMI. To complicate the picture, a low-T3S in the very first hours after AMI is considered protective since it lowers the energetic demand and predisposes the heart to regenerative repair [177]. On the other hand, previous studies have demonstrated that post-MI LV remodeling, a major determinant of morbidity and mortality in overt HF [178,179], is an early process. As a consequence, it is expected that an efficacious intervention aimed at preventing the initial stages of remodeling would better contrast the progression towards HF [176]. In accordance, Henderson et al. [18] showed that L-T3 replacement, initiated one week after MI, improved ventricular performance without reversing cardiac remodeling. On the other hand, early T3 replacement limited post-ischemic cardiomyocyte loss and blunted adverse cardiac remodeling $[19,98,99]$. With $\mathrm{TH}$ administration, it is also critical to choose the right dose in order to limit cardiac remodeling and avoid the potentially adverse systemic effects (i.e., thyrotoxicosis). In a previous study, an immediate long-term, but not controlled, supplementation of $\mathrm{TH}$ at a high dose in post-MI improved LV function and prevented cardiac remodeling, but also induced a thyrotoxic state [20], which in the long run may lead to heart dysfunction. These results were confirmed in a successive study demonstrating the dose-dependent bimodal effects of $\mathrm{TH}$ administration [91]. 


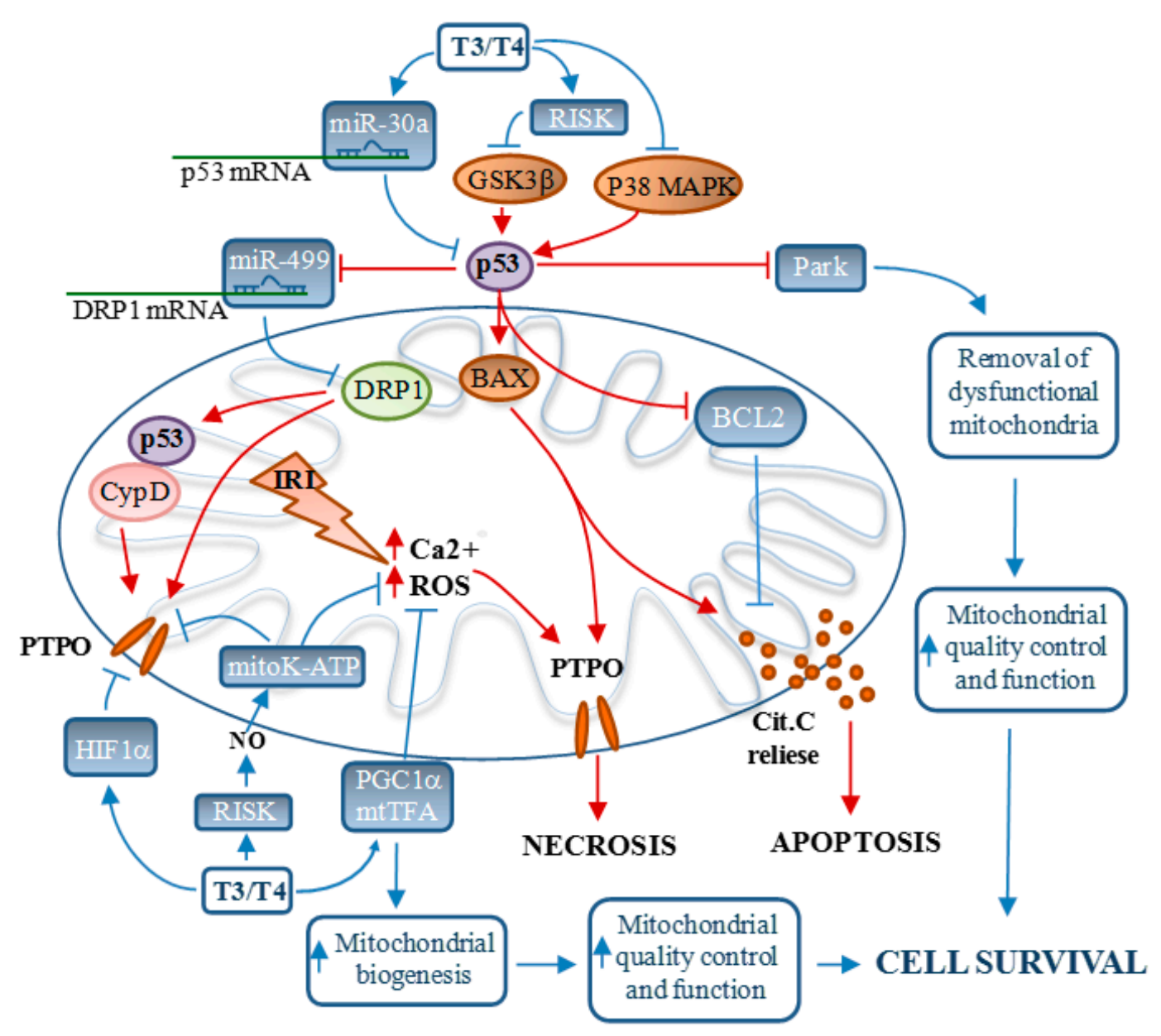

Figure 1. Schematic overview of the role of $\mathrm{TH}$ in the modulation of the mitochondrial pro-survival (blue connectors) or pro-death (red connectors) signaling networks that control cardiomyocyte fate in the I/R heart. CypD $=$ Cyclophilin $\mathrm{D}$; DRP1 = dynamin-related protein 1 ; GSK3 $\beta=$ glycogen synthase kinase $3-\beta$; HIF $1 \alpha=$ Hypoxia inducible factor $1 \alpha$, IRI $=$ ischemia/reperfusion injuries; mitoK-ATP $=$ mitochondrial ATP-dependent potassium channel; mtTFA $=$ mitochondrial transcription factor $\mathrm{A}$; Park = parkin; PTPO $=$ permeability transition pore opening; PGC1- $\alpha=$ peroxisome proliferator-activated receptor- $\gamma$ coactivator- $1 \alpha$; RISK $=$ reperfusion injury salvage kinase.

In conclusion, if we exclude the hyperacute post-MI period, the available evidence suggests that $\mathrm{TH}$ should be administered at a physiological or near-physiological dose in the early phase of the post-ischemic wound healing following reactivation of the endogenous regenerative process in order to obtain the maximal protective effect.

\section{Acknowledgments}

This work was funded by the Tuscany Region Research Grant (DGR 1157/2011) "Study of the molecular, biochemical and metabolic mechanisms involved in the cardioprotective effect of T3". 


\section{Abbreviations}

$\mathrm{AMI}=$ acute myocardial infarction; CypD $=$ Cyclophilin $\mathrm{D} ; \mathrm{DRP} 1=$ dynamin-related protein; GSK3 $\beta=$ glycogen synthase kinase $3-\beta$; HIF1 $\alpha=$ Hypoxia inducible factor $1 \alpha$; IRI = ischemia/ reperfusion injuries; Low T3 syndrome $=$ Low-T3S; mitoK-ATP $=$ mitochondrial ATP-dependent potassium channel; mtTFA $=$ mitochondrial transcription factor $\mathrm{A} ;$ Park $=$ parkin; $\mathrm{PGC1- \alpha =}$ peroxisome proliferator-activated receptor- $\gamma$ coactivator- $1 \alpha$; PTPO $=$ permeability transition pore opening; P38MAPK = P38 mitogen activated protein kinase; RISK = reperfusion injury salvage kinase.

\section{Conflicts of Interest}

The authors declare no conflict of interest.

\section{References}

1. Yellon, D.M.; Hausenloy, D.J. Myocardial reperfusion injury. N. Engl. J. Med. 2007, 357, 1121-1135.

2. Guzy, R.D.; Hoyos, B.; Robin, E.; Chen, H.; Liu, L.; Kyle, D.; Mansfield, K.D.; Simon, M.C.; Hammerling, U.; Schumacker, P.T. Mitochondrial complex III is required for hypoxia-induced ROS production and cellular oxygen sensing. Cell Metab. 2005, 1, 401-408.

3. Whelan, R.S.; Kaplinskiy, V.; Kitsis, R.N. Cell death in the pathogenesis of heart disease mechanisms and significance. Annu. Rev. Physiol. 2010, 72, 19-44.

4. Baines, C.P. The mitochondrial permeability transition pore and ischemia-reperfusion injury. Basic Res. Cardiol. 2009, 104, 181-188.

5. Marín-García, J.; Goldenthal, M.J. Mitochondrial centrality in heart failure. Heart Fail. Rev. 2008, 13, 137-150.

6. Galluzzi, L.; Kepp, O.; Kroemer, G. Mitochondria: Master regulators of danger signaling. Nat. Rev. Mol. Cell Biol. 2012, 13, 780-788.

7. Murry, C.E.; Jennings, R.B.; Reimer, K.A. Preconditioning with ischemia: A delay of lethal cell injury in ischemic myocardium. Circulation 1986, 74, 1124-1136.

8. Ovize, M.; Thibault, H.; Przyklenk, K. Myocardial conditioning: Opportunities for clinical translation. Circ. Res. 2013, 113, 439-450.

9. Gerdes, A.M.; Iervasi, G. Thyroid replacement therapy and heart failure. Circulation 2010, 122, 385-393.

10. Pingitore, A.; Chen, Y.; Gerdes, A.M.; Iervasi, G. Acute myocardial infarction and thyroid function: New pathophysiological and therapeutic perspectives. Ann. Med. 2012, 44, 745-757.

11. Mourouzis, I.; Forini, F.; Pantos, C.; Iervasi, G. Thyroid hormone and cardiac disease: From basic concepts to clinical application. J. Thyroid Res. 2011, 2011, doi:10.4061/2011/958626.

12. Nicolini, G.; Pitto, L.; Kusmic, C.; Balzan, S.; Sabatino, L.; Iervasi, G.; Forini, F. New insights into mechanisms of cardioprotection mediated by thyroid hormones. J. Thyroid Res. 2013, 2013, doi:10.1155/2013/264387.

13. Hamilton, M.A.; Stevenson, L.W.; Luu, M.; Walden, J.A. Altered thyroid hormone metabolism in advanced heart failure. J. Am. Coll. Cardiol. 1990, 16, 91-95. 
14. Wiersinga, W.M.; Lie, K.I.; Touber, J.L. Thyroid hormones in acute myocardial infarction. Clin. Endocrinol. (Oxf.) 1981, 14, 367-374.

15. Friberg, L.; Drvota, V.; Bjelak, A.H.; Eggertsen, G.; Ahnve, S. Association between increased levels of reverse triiodothyronine and mortality after acute myocardial infarction. Am. J. Med. 2001, 111, 699-703.

16. Iervasi, G.; Pingitore, A.; Landi, P.; Raciti, M.; Ripoli, A.; Scarlattini, M.; L'Abbate, A.; Donato, L. Low-T3 syndrome: A strong prognostic predictor of death in patients with heart disease. Circulation 2003, 107, 708-713.

17. Pingitore, A.; Galli, E.; Barison, A.; Iervasi, A.; Scarlattini, M.; Nucci, D.; L'abbate, A.; Mariotti, R.; Iervasi, G. Acute effects of triiodothyronine (T3) replacement therapy in patients with chronic heart failure and low-T3 syndrome: A randomized, placebo-controlled study. J. Clin. Endocrinol. Metab. 2008, 93, 1351-1358.

18. Henderson, K.K.; Danzi, S.; Paul, J.T.; Leya, G.; Klein, I.; Samarel, A.M. Physiological replacement of $\mathrm{t} 3$ improves left ventricular function in an animal model of myocardial infarction-induced congestive heart failure. Circ. Heart Fail. 2009, 2, 243-252.

19. Chen, Y.F.; Kobayashi, S.; Chen, J.; Redetzke, R.A.; Said, S.; Liang, Q.; Gerdes, A.M. Short term triiodo-Lthyronine treatment inhibits cardiac myocyte apoptosis in border area after myocardial infarction in rats. J. Mol. Cell. Cardiol. 2008, 44, 180-187.

20. Pantos, C.; Mourouzis, I.; Markakis, K.; Tsagoulis, N.; Panagiotou, M.; Cokkinos, D.V. Long term thyroid hormone administration reshapes left ventricular chamber and improves cardiac function after myocardial infarction in rats. Basic Res. Cardiol. 2008, 103, 308-318.

21. Wrutniak-Cabello, C.; Casas, F.; Cabello, G. Thyroid hormone action in mitochondria. J. Mol. Endocrinol. 2001, 26, 67-77.

22. Goldenthal, M.J.; Ananthakrishnan, R.; Marín-García, J. Nuclear-mitochondrial cross-talk in cardiomyocyte T3 signaling: A time-course analysis. J. Mol. Cell. Cardiol. 2005, 39, 319-326.

23. Marín-García, J. Thyroid hormone and myocardial mitochondrial biogenesis. Vascul. Pharmacol. 2010, 52, 120-130.

24. Shintani-Ishida, K.; Inui, M.; Yoshida, K. Ischemia-reperfusion induces myocardial infarction through mitochondrial $\mathrm{Ca}^{2+}$ overload. J. Mol. Cell. Cardiol. 2012, 53, 233-239.

25. Herzig, S.; Maundrell, K.; Martinou, J.C. Life without the mitochondrial calcium uniporter. Nat. Cell Biol. 2013, 15, 1398-1400.

26. Tompkinsa, A.J.; Burwellb, L.; Digernessc, S.B.; Zaragozac, C.; Holmanc, W.L.; Brookesa, P.S. Mitochondrial dysfunction in cardiac ischemia-reperfusion injury: ROS from complex I, without inhibition. BBA Mol. Basis Dis. 2006, 1762, 223-231.

27. Dorn, G.W., II. Apoptotic and non-apoptotic programmed cardiomyocyte death in ventricular remodeling. Cardiovasc. Res. 2009, 81, 465-473.

28. Dröse, S.1.; Brandt, U. Molecular mechanisms of superoxide production by the mitochondrial respiratory chain. Adv. Exp. Med. Biol. 2012, 748, 145-169.

29. Becker, L.B. New concepts in reactive oxygen species and cardiovascular reperfusion physiology. Cardiovasc. Res. 2004, 61, 461-470. 
30. Assaly, R.; d'Anglemont de Tassigny, A.; Paradis, S.; Jacquin, S.; Berdeaux, A.; Morin, D. Oxidative stress, mitochondrial permeability transition pore opening and cell death during hypoxia-reoxygenation in adult Cardiomyocytes. Eur. J. Pharmacol. 2012, 675, 6-14.

31. Ide, T.; Tsutsui, H.; Hayashidani, S.; Kang, D.; Suematsu, N.; Nakamura, K.; Utsumi, H.; Hamasaki, N.; Takeshita, A. Mitochondrial DNA damage and dysfunction associated with oxidative stress in failing hearts after myocardial infarction. Circ. Res. 2001, 88, 529-535.

32. Dai, D.F.; Chen, T.; Szeto, H.; Nieves-Cintrón, M.; Kutyavin, V.; Santana, L.F.; Rabinovitch, P.S. Mitochondrial targeted antioxidant Peptide ameliorates hypertensive cardiomyopathy. J. Am. Coll. Cardiol. 2011, 58, 73-82.

33. Baines, C.P. The cardiac mitochondrion: Nexus of stress. Annu. Rev. Physiol. 2010, 72, 61-80.

34. Brady, N.R.; Hamacher-Brady, A.; Gottlieb, R.A. Proapoptotic BCL-2 family members and mitochondrial dysfunction during ischemia/reperfusion injury, a study employing cardiac HL-1 cells and GFP biosensors. Biochim. Biophys. Acta 2006, 1757, 667-678.

35. Zorov, D.B.; Filburn, C.R.; Klotz, L.O.; Zweier, J.L.; Sollott, S.J. Reactive oxygen species (ROS)-induced ROS release: A new phenomenon accompanying induction of the mitochondrial permeability transition in cardiac myocytes. J. Exp. Med. 2000, 192, 1001-1014.

36. Garcia-Dorado, D.; Ruiz-Meana, M.; Inserte, J.; Rodriguez-Sinovas, A.; Piper, H.M. Calcium-mediated cell death during myocardial reperfusion. Cardiovasc. Res. 2012, 94, 168-180.

37. McStay, G.P.; Clarke, S.J.; Halestrap, A.P. Role of critical thiol groups on the matrix surface of the adenine nucleotide translocase in the mechanism of the mitochondrial permeability transition pore. Biochem. J. 2002, 367, 541-548.

38. Leung, A.W.C.; Varanyuwatana, P.; Halestrap, A.P. The mitochondrial phosphate carrier interacts with cyclophilin D and may play a key role in the permeability transition J. Biol. Chem. 2008, 283, 26312-26323.

39. Kwong, J.; Davis, C.P.; Baines, M.A.; Sargent, J.; Karch, X.; Wang, X.; Huang, T., Molkentin, J.D. Genetic deletion of the mitochondrial phosphate carrier desensitizes the mitochondrial permeability transition pore and causes cardiomyopathy. Cell Death Differ. 2014, 21, 1209-1217.

40. Paul, A.; Wilson, S.; Belham, C.M.; Robinson, C.J.; Scott, P.H.; Gould, G.W.; Plevin, R. Stress-activated protein kinases: Activation, regulation and function. Cell Signal. 1997, 9, 403-410.

41. Ma, X.L.; Kumar, S.; Gao, F.; Louden, C.S.; Lopez, B.L.; Christopher, T.A.; Wang, C.; Lee, J.C.; Feuerstein, G.Z.; Yue, T.L. Inhibition of p38 mitogen-activated protein kinase decreases cardiomyocyte apoptosis and improves cardiac function after myocardial ischemia and reperfusion. Circulation 1999, 99, 1685-1689.

42. Dhingra, S.; Sharma, A.K.; Singla, D.K.; Singal, P.K. p38 and ERK1/2 MAPKs mediate the interplay of TNF- $\alpha$ and IL-10 in regulating oxidative stress and cardiac myocyte apoptosis. Am. J. Physiol. Heart Circ. Physiol. 2007, 293, H3524-H3531.

43. Ashraf, M.I.; Ebner, M.; Wallner, C.; Haller, M.; Khalid, S.; Schwelberger, H.; Koziel, K.; Enthammer, M.; Hermann, M.; Sickinger, S.; et al. A p38MAPK/MK2 signaling pathway leading to redox stress, cell death and ischemia/reperfusion injury. Cell Commun. Signal. 2014, 12, doi:10.1186/1478-811X-12-6.

44. Ren, J.; Zhang, S.; Kovacs, A.; Wang, Y.; Muslin, A.J. Role of p38 a MAPK in cardiac apoptosis and remodeling after myocardial infarction. J. Mol. Cell. Cardiol. 2005, 38, 617-623. 
45. Capano, M.; Crompton, M. Bax translocates to mitochondria of heart cells during simulated ischaemia: Involvement of AMP-activated and p38 mitogen-activated protein kinases. Biochem. J. 2006, 395, 57-64.

46. Martin, E.D.; de Nicola, G.F.; Marber, M.S. New therapeutic targets in cardiology: p38 $\alpha$ mitogen-activated protein kinase for ischemic heart disease. Circulation 2012, 126, 357-368.

47. Kaiser, R.A.; Bueno, O.F.; Lips, D.J.; Doevendans, P.A.; Jones, F.; Kimball, T.F.; Molkentin, J.D. Targeted inhibition of p38 mitogen-activated protein kinase antagonizes cardiac injury and cell death following ischemia-reperfusion in vivo. J. Biol. Chem. 2004, 279, 15524-15530.

48. Jeong, C.W.; Yoo, K.Y.; Lee, S.H.; Jeong, H.J.; Lee, C.S.; Kim, S. Curcumin protects against regional myocardial ischemia/reperfusion injury through activation of RISK/GSK-3 $\beta$ and inhibition of p38 MAPK and JNK. J. Cardiovasc. Pharmacol. Ther. 2012, 17, 387-394.

49. Genovese, T.; Impellizzeri, D.; Ahmad, A.; Cornelius, C.; Campolo, M.; Cuzzocrea, S.; Esposito, E. Post ischaemic thyroid hormone treatment in a rat model of acute stroke. Brain Res. 2013, 1513, 92-102.

50. Pantos, C.; Malliopoulou, V.; Mourouzis, I.; Karamanoli, E.; Tzeis, S.M.; Carageorgiou, H.; Varonos, D.; Cokkinos, D.V. Long-term thyroxine administration increases HSP70 mRNA expression and attenuates p38 MAP kinase activity in response to ischaemia. J. Endocrinol. 2001, 70, 207-215.

51. Pantos, C.; Mourouzis, I.; Saranteas, T.; Clavé, G.; Ligeret, H.; Noack-Fraissignes, P.; Renard, P.Y.; Massonneau, M.; Perimenis, P.; Spanou, D.; et al. Thyroid hormone improves postischaemic recovery of function while limiting apoptosis: A new therapeutic approach to support hemodynamics in the setting of ischaemia-reperfusion? Basic Res. Cardiol. 2009, 104, 69-77.

52. Mourouzis, I.; Kostakou, E.; Galanopoulos, G.; Mantzouratou, P.; Pantos, C. Inhibition of thyroid hormone receptor $\alpha 1$ impairs post ischemic cardiac performance after myocardial infarction in mice. Mol. Cell. Biochem. 2013, 379, 97-105.

53. Vousden, K.H. p53, death star. Cell 2000, 103, 691-694.

54. Miyashita, T.; Reed, J. Tumor suppressor p53 is a direct transcriptional activator of the human bax gene. Cell 1995, 80, 293-299.

55. Long, X.; Boluyt, M.O.; Hipolito, M.; Lundberg, M.S.; Zheng, J.S.; O’Neill, L.; Cirielli, C.; Lakatta, E.G.; Crow, M.T. p53 and the hypoxia-induced apoptosis of cultured neonatal rat cardiac myocytes. J. Clin. Investig. 1997, 99, 2635-2643.

56. Vaseva, A.V.; Marchenko, N.D.; Ji, K.; Tsirka, S.E.; Holzmann, S.; Moll, U.M. p53 opens the mitochondrial permeability transition pore to trigger necrosis. Cell 2012, 149, 1536-1548.

57. Ong, S.B.; Hausenloy, D.J. Mitochondrial morphology and cardiovascular disease. Cardiovasc. Res. 2010, 88, 16-29.

58. Dieter, A.; Kubli, Å.B. Gustafsson mitochondria and mitophagy: The yin and yang of cell death control. Circ. Res. 2012, 111, 1208-1221.

59. Dimmer, K.S.; Scorrano, L. (De)constructing mitochondria: What for? Physiology 2006, 21, 233-241.

60. Hausenloy, D.J.; Scorrano, L. Targeting cell death. Clin. Pharmacol. Ther. 2007, 82, 370-373. 
61. Shen, T.; Zheng, M.; Cao, C.; Chen, C.; Tang, J.; Zhang, W.; Cheng, H.; Chen, K.H.; Xiao, R.P. Mitofusin-2 is a major determinant of oxidative stress-mediated heart muscle cell apoptosis. J. Biol. Chem. 2007, 282, 23354-23361.

62. Ong, S.B.; Subrayan, S.; Lim, S.Y.; Yellon, D.M.; Davidson, S.M.; Hausenloy, D.J. Inhibiting mitochondrial fission protects the heart against ischemia/reperfusion injury. Circulation 2010, 121, 2012-2202.

63. Kong, D.; Xu, L.; Yu, Y.; Zhu, W.; Andrews, D.W.; Yoon, Y.; Kuo, T.H. Regulation of Ca ${ }^{2+}$-induced permeability transition by Bcl-2 is antagonized by Drpl and hFis1. Mol. Cell Biochem. 2005, 272, 187-199.

64. Wang, J.; Jiao, J.; Li, Q.; Long, B.; Wang, K.; Liu, J.; Li, Y.; Li, P. miR-499 regulates mitochondrial dynamics by targeting calcineurin and dynamin-related protein-1. Nat. Med. 2011, $17,71-78$.

65. Guo, X.; Sesaki, H.H.; Qi, X. Drp1 stabilizes p53 on the mitochondria to trigger necrosis under oxidative stress conditions in vitro and in vivo. Biochem. J. 2014, 461, 137-146.

66. Whelan, R.S.; Konstantinidis, K.; Wei, A.C.; Chen, Y.; Reyna, D.E.; Jha, S.; Yang, Y.; Calvert, J.W.; Lindsten, T.; Thompson, C.B.; et al. Bax regulates primary necrosis through mitochondrial dynamics. Proc. Natl. Acad. Sci. USA 2012, 109, 6566-6571.

67. Wohlgemuth, S.E.; Calvani, R.; Marzetti, E. The interplay between autophagy and mitochondrial dysfunction in oxidative stress-induced cardiac aging and pathology. J. Mol. Cell. Cardiol. 2014, $71,62-70$.

68. Chen, Y.; Dorn, G.W., II. PINK1-phosphorylated mitofusin 2 is a Parkin receptor for culling damaged mitochondria. Science 2013, 340, 471-475.

69. Narendra, D.; Tanaka, A.; Suen, D.F.; Youle, R.J. Parkin is recruited selectively to impaired mitochondria and promotes their autophagy. J. Cell Biol. 2008, 183, 795-803.

70. Hoshino, A.; Mita, Y.; Okawa, Y.; Ariyoshi, M.; Iwai-Kanai, E.; Ueyama, T.; Ikeda, K.; Ogata, T.; Matoba, S. Cytosolic p53 inhibits Parkin-mediated mitophagy and promotes mitochondrial dysfunction in the mouse heart. Nat. Commun. 2013, 4, doi:10.1038/ncomms3308.

71. Hoshino, A.; Matoba, S.; Iwai-Kanai, E.; Nakamura, H.; Kimata, M.; Nakaoka, M.; Katamura, M.; Okawa, Y.; Ariyoshi, M.; Mita, Y.; et al. p53-TIGAR axis attenuates mitophagy to exacerbate cardiac damage after ischemia. J. Mol. Cell. Cardiol. 2012, 52, 1175-1184.

72. Cohen, P.; Frame, S. The renaissance of GSK3B. Nat. Rev. Mol. Cell Biol. 2001, 2, 769-776.

73. Sussman, M.A.; Völkers, M.; Fischer, K.; Bailey, B.; Cottage, C.T.; Din, S.; Gude, N.; Avitabile, D.; Alvarez, R.; Sundararaman, B.; et al. Myocardial AKT: The omnipresent nexus. Physiol. Rev. 2011, 91, 1023-1070.

74. Hausenloy, D.J.; Yellon, D.M. New directions for protecting the heart against ischaemia-reperfusion injury: Targeting the Reperfusion Injury Salvage Kinase (RISK)-pathway. Cardiovasc. Res. 2004, 61, 448-460.

75. Linseman, D.A.; Butts, B.D.; Precht, T.A.; Phelps, R.A.; Le, S.S.; Laessig, T.A.; Bouchard, R.J.; Florez-McClure, M.L.; Heidenreich, K.A. Glycogen synthase kinase-3 $\beta$ phosphorylates Bax and promotes its mitochondrial localization during neuronal apoptosis. J. Neurosci. 2004, 24, 9993-10002. 
76. Juhaszova, M.; Zorov, D.B.; Kim, S.H.; Pepe, S.; Fu, Q.; Fishbein, K.W.; Ziman, B.D.; Wang, S.; Ytrehus, K.; Antos, C.L.; et al. Glycogen synthase kinase-3 $\beta$ mediates convergence of protection signaling to inhibit the mitochondrial permeability transition pore. J. Clin. Investig. 2004, 113, 1535-1549.

77. Gomez, L.; Paillard, M.; Thibault, H.; Derumeaux, G.; Ovize, M. Inhibition of GSK3 $\beta$ by postconditioning is required to prevent opening of the mitochondrial permeability transition pore during reperfusion. Circulation 2008, 117, 2761-2768.

78. Watcharasit, P.; Bijur, G.N.; Song, L.; Zhu, J.; Chen, X.; Jope, R.S. Glycogen synthase kinase-3b(GSK3b) binds to and promotes the actions of p53. J. Biol. Chem. 2003, 278, 48872-48879.

79. Rasola, A.; Sciacovelli, M.; Chiara, F.; Pantic, B.; Brusilow, W.S.; Bernardi, P. Activation of mitochondrial ERK protects cancer cells from death through inhibition of the permeability transition. Proc. Natl. Acad. Sci. USA 2010, 107, 726-731.

80. Phukan, S.; Babu, V.S.; Kannoji, A.; Hariharan, R.; Balaji, V.N. GSK3ß: Role in therapeutic landscape and development of modulators. Br. J. Pharmacol. 2010, 160, 1-19.

81. Tanno, M.; Kuno, A.; Ishikawa, S.; Miki, T.; Kouzu, H.; Yano, T.; Murase, H.; Tobisawa, T.; Ogasawara, M.; Horio, Y.; et al. Translocation of Glycogen Synthase Kinase-3 $\beta$ (GSK-3 $\beta$ ), a trigger of permeability transition, is kinase activity dependent and mediated by interaction with voltage-dependent anion channel 2 (VDAC2). J. Biol. Chem. 2014, 289, 29285-29296.

82. Gross, G.J.; Hsu, A.; Pfeiffer, A.W.; Nithipatikom, K. Roles of endothelial nitric oxide synthase (eNOS) and mitochondrial permeability transition pore (MPTP) in epoxyeicosatrienoic acid (EET)-induced cardioprotection against infarction in intact rat hearts. J. Mol. Cell. Cardiol. 2013, 59, 20-29.

83. Sasaki, N.; Sato, T.; Ohler, A.; O'Rourke, B.; Marbán, E. Activation of mitochondrial ATP-dependent potassium channels by nitric oxide. Circulation 2000, 101, 439-445.

84. Penna, C.; Rastaldo, R.; Mancardi, D.; Raimondo, S.; Cappello, S.; Gattullo, D.; Losano, G.; Pagliario, P. Post-conditioning induced cardioprotection requires signaling through a redox-sensitive mechanism, mitochondrial ATP-sensitive $\mathrm{K}^{+}$channel and protein kinase $\mathrm{C}$ activation. Basic Res. Cardiol. 2006, 101, 180-189.

85. Gucek, M.; Murphy, E. What can we learn about cardioprotection from the cardiac mitochondrial proteome? Cardiovasc. Res. 2010, 88, 211-218.

86. Burwell, L.S.; Brookes, P.S. Mitochondria as a target for the cardioprotective effects of nitric oxide in ischemia-reperfusion injury. Antioxid. Redox Signal. 2008, 10, 579-599.

87. Ong, S.B.; Hall, A.R.; Dongworth, R.K.; Kalkhoran, S.; Pyakurel, A.; Scorrano, L.; Hausenloy, D.J. Akt protects the heart against ischaemia/reperfusion injury by modulating mitochondrial morphology. Thromb. Haemost. 2015, 113, 513-516.

88. Kenessey, A.; Ojamaa, K. Thyroid hormone stimulates protein synthesis in the cardiomyocyte by activating the Akt-mTOR and p70S6Kpathways. J. Biol. Chem. 2006, 28, 20666-20672.

89. Kuzman, J.A.; Gerdes, A.M.; Kobayashi, S.; Liang, Q. Thyroid hormone activates Akt and prevents serum starvation-induced cell death in neonatal rat cardiomyocytes. J. Mol. Cell. Cardiol. 2005, 39, 841-844. 
90. Kuzman, J.A.; Vogelsang, K.A.; Thomas, T.A.; Gerdes, A.M. L-Thyroxine activates Akt signaling in the heart. J. Mol. Cell. Cardiol. 2005, 39, 251-258.

91. Mourouzis, I.; Mantzouratou, P.; Galanopoulos, G.; Kostakou, E.; Roukounakis, N.; Kokkinos, A.D.; Cokkinos, D.V.; Pantos, C. Dose-dependent effects of thyroid hormone on post-ischemic cardiac performance: Potential involvement of Akt and ERK signalings. Mol. Cell. Biochem. 2012, 363, 235-243.

92. Kehat, I.; Davis, J.; Tiburcy, M.; Accornero, F.; Saba-El-Leil, M.K.; Maillet, M.; York, A.J.; Lorenz, J.N.; Zimmermann, W.H.; Meloche, S.; et al. Extracellular signal-regulated kinases 1 and 2 regulate the balance between eccentric and concentric cardiac growth. Circ. Res. 2010, 108, 176-183.

93. Naito, A.T.; Okada, S.; Minamino, T.; Iwanaga, K.; Liu, M.L.; Sumida, T.; Nomura, S.; Sahara, N.; Mizoroki, T.; Takashima, A.; et al. Promotion of chip-mediated p53 degradation protects the heart from ischemic injury. Circ. Res. 2010, 106, 1692-1702.

94. Lin, H.Y.; Davis, P.J.; Tang, H.Y.; Mousa, S.A.; Luidens, M.K.; Hercbergs, A.H.; Davis, F.B. The pro-apoptotic action of stilbene-induced COX-2 in cancer cells: Convergence with the anti-apoptotic effect of thyroid hormone. Cell Cycle 2009, 8, 1877-1882

95. Lin, H.Y.; Tang, H.Y.; Keating, T.; Wu, Y.H.; Shih, A.; Hammond, D.; Sun, M.; Hercbergs, A.; Davis, F.B.; Davis, P.J. Resveratrol is pro-apoptotic and thyroid hormone is anti-apoptotic in glioma cells: Both actions are integrin and ERK mediated. Carcinogenesis 2008, 29, 62-69.

96. Yap, N.; Yu, C.L.; Cheng, S.Y. Modulation of thetrascriptional activity ofthyroid hormone receptor by the tumor suppressor p53. Proc. Natl. Acad. Sci. USA 1996, 93, 4273-4277.

97. Bhat, M.K.; Yu, C.1.; Yap, N.; Zhan, Q.; Hayashi, Y.; Seth, P. Tumor suppressor p53 is a negative regulator in thyroid hormone receptor signaling pathways. J. Biol. Chem. 1997, 272, 28989-28993.

98. Forini, F.; Kusmic, C.; Nicolini, G.; Mariani, L.; Zucchi, R.; Matteucci, M.; Iervasi, G.; Pitto, L. Triiodothyronine prevents cardiac ischemia/reperfusion mitochondrial impairment and cell loss by regulating miR30a/p53 axis. Endocrinology 2014, 155, 4581-4590.

99. Forini, F.; Lionetti, V.; Ardehali, H.; Pucci, A.; Cecchetti, F.; Ghanefar, M.; Nicolini, G.; Ichikawa, Y.; Nannipieri, M.; Recchia, F.A.; et al. Early long-term L-T3 replacement rescues mitochondria and prevents ischemic cardiac remodelling in rats. J. Cell. Mol. Med. 2011, 15, 514-524.

100. Yusuf, S.; Dagenais, G.; Pogue, J.; Bosch, J.; Sleight, P. Vitamin E supplementation and cardiovascular events in high-risk patients. The heart outcomes prevention evaluation study investigators. N. Engl. J. Med. 2000, 342, 154-160.

101. Hare, J.M.; Mangal, B.; Brown, J.; Fisher, C., Jr.; Freudenberger, R.; Colucci, W.S.; Mann, D.L.; Liu, P.; Givertz, M.M.; Schwarz, R.P.; OPT-CHF Investigators. Impact of oxypurinol in patients with symptomatic heart failure: Results of the OPT-CHF study. J. Am. Coll. Cardiol. 2008, 5, 2301-2309.

102. Brown, D.A.; Hale, S.L.; Baines, C.P.; del Rio, C.L.; Hamlin, R.L.; Yueyama, Y.; Kijtawornrat, A.; Yeh, S.T.; Frasier, C.R.; Stewart, L.M.; et al. Reduction of early reperfusion injury with the mitochondria-targeting peptide bendavia. J. Cardiovasc. Pharmacol. Ther. 2014, 19, 121-132. 
103. Adlam, V.J.; Harrison, J.C.; Porteous, C.M.; James, A.M.; Smith, R.A.; Murphy, M.P.; Sammut, I.A. Targeting an antioxidant to mitochondria decreases cardiac ischemia-reperfusion injury. FASEB J. 2005, 19, 1088-1095.

104. Szeto, H.H. Mitochondria-targeted cytoprotective peptides for ischemia-reperfusion injury. Antiox. Redox Signal. 2008, 10, 601-619.

105. Zhao, K.; Zhao, G.M.; Wu, D.; Soong, Y.; Birk, A.V.; Schiller, P.W.; Szeto, H.H. Cell-permeable peptide antioxidants targeted to inner mitochondrial membrane inhibit mitochondrial swelling, oxidative cell death, and reperfusion injury. J. Biol. Chem. 2004, 279, 34682-34690.

106. De Castro, A.L.; Tavares, A.V.; Campos, C.; Fernandes, R.O.; Siqueira, R.; Conzatti, A.; Bicca, A.M.; Fernandes, T.R.; Sartório, C.L.; Schenkel, P.C.; et al. Cardioprotective effects of thyroid hormones ina rat model of myocardial infarction are associated with oxidative stress reduction. Mol. Cell. Endocrinol. 2014, 391, 22-29.

107. Di Lisa, F.; Menabò, R.; Canton, M.; Barile, M.; Bernardi, P. Opening of the mitochondrial permeability transition pore causes depletion of mitochondrial and cytosolic $\mathrm{NAD}^{+}$and is a causative event in the death of myocytes in postischemic reperfusion of the heart. J. Biol. Chem. 2001, 276, 2571-2575.

108. Clarke, S.J.; McStay, G.P.; Halestrap, A.P. Sanglifehrin A acts as a potent inhibitor of the mitochondrial permeability transition and reperfusion injury of the heart by binding to cyclophilin-D at a different site from cyclosporin A. J. Biol. Chem. 2002, 277, 34793-34799.

109. Nakayama, H.; Chen, X.; Baines, C.P.; Klevitsky, R.; Zhang, X.; Zhang, H.; Jaleel, N.; Chua, B.H.; Hewett, T.E.; Robbins, J.; et al. $\mathrm{Ca}^{2+}$ - and mitochondrial-dependent cardiomyocyte necrosis as a primary mediator of heart failure. J. Clin. Investig. 2007, 117, 2431-2444.

110. Nakagawa, T.; Shimizu, S.; Watanabe, T.; Yamaguchi, O.; Otsu, K.; Yamagata, H.; Inohara, H.; Kubo, T.; Tsujimoto, Y. Cyclophilin D-dependent mitochondrial permeability transition regulates some necrotic but not apoptotic cell death. Nature 2005, 434, 652-658.

111. Kato, M.; Akao, M.; Matsumoto-Ida, M.; Makiyama, T.; Iguchi, M.; Takeda, T.; Shimizu, S.; Kita, T. The targeting of cyclophilin D by RNAi as a novel cardioprotective therapy: Evidence from two-photon imaging. Cardiovasc. Res. 2009, 83, 335-344.

112. Elrod, J.W.; Wong, R.; Mishra, S.; Vagnozzi, R.J.; Sakthievel, B.; Goonasekera, S.A.; Karch, J.; Gabel, S.; Farber, J.; Force, T.; et al. Cyclophilin D controls mitochondrial pore-dependent $\mathrm{Ca}^{2+}$ exchange, metabolic flexibility, and propensity for heart failure in mice. J. Clin. Investig. 2010, 120, 3680-3687.

113. Piot, C.; Croisille, P.; Staat, P.; Thibault, H.; Rioufol, G.; Mewton, N.; Elbelghiti, R.; Cung, T.T.; Bonnefoy, E.; Angoulvant, D.; et al. Effect of cyclosporine on reperfusion injury in acute myocardial infarction. N. Engl. J. Med. 2008, 359, 473-448.

114. Fuglesteg, B.N.; Suleman, N.; Tiron, C.; Kanhema, T.; Lacerda, L.; Andreasen, T.V.; Sack, M.N.; Janassen, A.K.; Mjos, O.D.; Opie, L.H.; et al. Signal transducer and activator of transcription 3 is involved in the cardioprotective signaling pathway activated by insulin therapy at reperfusion. Bas. Res. Cardiol. 2008, 103, 444-453.

115. Lacerda, L.; Somers, S.; Opie, L.H.; Lecour, S. Ischemic postconditioning protect against reperfusion injury via SAFE pathway. Cardiovasc. Res. 2009, 84, 201-208. 
116. Boengler, K.; Hilfiker-Kleiner, D.; Heusch, G.; Schulz, R. Inhibition of permeability transition pore opening by mitochondrial STAT3 and its role in myocardial ischemia/reperfusion. Basic Res. Cardiol. 2010, 105, 771-785.

117. Hataishi, R.; Rodrigues, A.C.; Neilan, T.G.; Morgan, J.G.; Buys, E.; Shiva, S.; Tambouret, R.; Jassal, D.S.; Raher, M.J.; Furutani, E.; et al. Inhaled nitric oxide decreases infarction size and improves left ventricular function in a murine model of myocardial ischemia-reperfusion injury. Am. J. Physiol. Heart Circ. Physiol. 2006, 291, H379-H384.

118. Nagasaka, Y.; Fernandez, B.O.; Garcia-Saura, M.F.; Petersen, B.; Ichinose, F.; Bloch, K.D.; Feelisch, M.; Zapol, W.M. Brief periods of nitric oxide inhalation protect against myocardial ischemia-reperfusion injury. Anesthesiology 2008, 109, 675-682.

119. Liu, X.; Huang, Y.; Pokreisz, P.; Vermeersch, P.; Marsboom, G.; Swinnen, M.; Verbeken, E.; Santos, J.; Pellens, M.; Gillijns, H.; et al. Nitric oxide inhalation improves microvascular flow and decreases infarction size after myocardial ischemia and reperfusion. J. Am. Coll. Cardiol. 2007, 50, 808-817.

120. Wang, G.; Liem, D.A.; Vondriska, T.M.; Honda, H.M.; Korge, P.; Pantaleon, D.M.; Qiao, X.; Wang, Y.; Weiss, J.N.; Ping, P. Nitric oxide donors protect murine myocardium against infarction via modulation of mitochondrial permeability transition. Am. J. Physiol. Heart Circ. Physiol. 2005, 288, H1290-H1295.

121. Ong, S.G.; Hausenloy, D.J. Hypoxia-inducible factor as a therapeutic target for cardioprotection. Pharmacol. Ther. 2012, 136, 69-81.

122. Ong, S.G.; Lee, W.H.; Theodorou, L.; Kodo, K.; Lim, S.Y.; Shukla, D.H.; Briston, T.; Kiriakidis, S.; Ashcroft, M.; Davidson, S.M.; et al. HIF-1 reduces ischaemia-reperfusion injury in the heart by targeting the mitochondrial permeability transition pore. Cardiovasc. Res. 2014, 104, 24-36.

123. Benard, G.; Bellance, N.; Jose, C.; Melser, S.; Nouette-Gaulain, K.; Rossignol, R. Multi-site control and regulation of mitochondrial energy production. Biochim. Biophys. Acta 2010, 1797, 698-709.

124. McLeod, C.J.; Pagel, I.; Sack, M.N. The mitochondrial biogenesis regulatory program adaptation to ischemia-A putative target for therapeutic intervention. Trends Cardiovasc. Med. 2005, 15, $118-123$.

125. Hock, M.B.; Kralli, A. Transcriptional control of mitochondrial biogenesis and function. Annu. Rev. Physiol. 2009, 71, 177-203.

126. Ventura-Clapier, R.; Garnier, A.; Veksler, V. Transcriptional control of mitochondrial biogenesis: The central role of PGC-1 $\alpha$. Cardiovasc. Res. 2008, 79, 208-217.

127. Ventura-Clapier, R.; Garnier, A.; Veksler, V.; Joubert, F. Bioenergetics of the failing heart. Biochim. Biophys. Acta 2011, 1813, 1360-1372.

128. Garnier, A.; Fortin, D.; Deloménie, C.; Momken, I.; Veksler, V.; Ventura-Clapier, R. Depressed mitochondrial transcription factors and oxidative capacity in rat failing cardiac and skeletal muscles. J. Physiol. 2003, 551, 491-501.

129. Watson, P.A.; Reusch, J.E.; McCune, S.A.; Leinwand, L.A.; Luckey, S.W.; Konhilas, J.P. Restoration of CREB function is linked to completion and stabilization of adaptive cardiac hypertrophy in response to exercise. Am. J. Physiol. 2007, 293, H246-H259. 
130. Lehman J.J.; Kelly, D.P. Transcriptional activation of energy metabolic switches in the developing and hypertrophied heart. Clin. Exp. Pharmacol. Physiol. 2002, 29, 339-345.

131. Arany, Z.; Novikov, M.; Chin, S.; Ma, Y.; Rosenzweig, A.; Spiegelman, B.M. Transverse aortic constriction leads to accelerated heart failure in mice lacking PPAR $\gamma$ coactivator $1 \alpha$. Proc. Natl. Acad. Sci. USA 2006, 103, 10086-10091.

132. Sihag, S.; Li, A.Y.; Cresci, S.; Sucharov, C.C.; Lehman, J.J. PGC-1 $\alpha$ and ERR $\alpha$ target gene down-regulation is a signature of the failing human heart J. Mol. Cell. Cardiol. 2009, 46, 201-212.

133. Ahuja, P.; Zhao, P.; Angelis, E.; Ruan, H.; Korge, P.; Olson, A.; Wang, Y.; Jin, E.S.; Jeffrey, F.M.; Portman, M.; et al. Myc controls transcriptional regulation of cardiac metabolism and mitochondrial biogenesis in response to pathological stress in mice. J. Clin. Investig. 2010, 120, 1494-1505.

134. Yan, W.; Zhang, H.; Liu, P.; Wang, H.; Liu, J.; Gao, C.; Liu, Y.; Lian, K.; Yang, L.; Sun, L.; et al. Impaired mitochondrial biogenesis due to dysfunctional adiponectin-AMPK-PGC-1 $\alpha$ signaling contributing to increased vulnerability in diabetic heart. Basic Res. Cardiol. 2013, 108, doi:10.1007/s00395-013-0329-1.

135. Sun, L.; Zhao, M.; Yu, X.J.; Wang, H.; He, X.; Liu, J.K.; Zang, W.J. Cardioprotection by acetylcholine: A novel mechanism via mitochondrial biogenesis and function involving the PGC-1 $\alpha$ pathway. J. Cell. Physiol. 2013, 228, 1238-1248.

136. St-Pierre, J.; Lin, J.; Krauss, S.; Tarr, P.T.; Yang, R.; Newgard, C.B.; Spiegelman, B.M. Bioenergetic analysis of peroxisome proliferator-activated receptor gamma coactivators $1 \alpha$ and $1 \beta$ (PGC-1 $\alpha$ and PGC-1 $\beta$ ) in muscle cells. J. Biol. Chem. 2003, 278, 26597-26603.

137. Kajander, O.A.; Karhunen, P.J.; Jacobs, H.T. The relationship between somatic mtDNA rearrangements, human heart disease and aging. Hum. Mol. Genet. 2002, 11, 317-324.

138. Naya, F.J.; Black, B.L.; Wu, H.; Bassel-Duby, R.; Richardson, J.A.; Hill, J.A.; Olson, E.N. Mitochondrial deficiency and cardiac sudden death in mice lacking the MEF2A transcription factor. Nat. Med. 2002, 8, 1303-1309.

139. Lebrecht, D.; Setzer, B.; Ketelsen, U.P.; Haberstroh, J.; Walker, U.A. Timedependent and tissue-specific accumulation of mtDNA and respiratory chain defects in chronic doxorubicin cardiomyopathy. Circulation 2003, 108, 2423-2429.

140. Ide, T.; Tsutsui, H.; Kinugawa, S.; Utsumi, H.; Kang, D.; Hattori, N.; Uchida, K.; Arimura, K.; Egashira, K.; Takeshita, A. Mitochondrial electron transport complex I is a potential source of oxygen free radicals in the failing myocardium. Circ. Res. 1999, 85, 357-363.

141. Li, H.; Wang, J.; Wilhelmsson, H.; Hansson, A.; Thoren, P.; Duffy, J.; Rustin, P.; Larsson, N.G. Genetic modification of survival in tissue-specific knockout mice with mitochondrial cardiomyopathy. Proc. Natl. Acad. Sci. USA 2000, 97, 3467-3472.

142. Wang, J.; Wilhelmsson, H.; Graff, C.; Li, H.; Oldfors, A.; Rustin, P.; Bruning, J.C.; Kahn, C.R.; Clayton, D.A.; Barsh, G.S.; et al. Dilated cardiomyopathy and atrioventricular conduction blocks induced by heart-specific inactivation of mitochondrial DNA gene expression. Nat. Genet. 1999, $21,133-137$. 
143. Ikeuchi, M.; Matsusaka, H.; Kang, D.; Matsushima, S.; Ide, T.; Kubota, T.; Fujiwara, T.; Hamasaki, N.; Takeshita, A.; Sunagawa, K.; et al. Overexpression of mitochondrial transcription factor a ameliorates mitochondrial deficiencies and cardiac failure after myocardial infarction. Circulation 2005, 112, 683-669.

144. Guarente, L. Sirtuins in aging and disease. Cold Spring Harb. Symp. Quant. Biol. 2007, 72, 483-488.

145. Nakagawa, T.; Guarente, L. Sirtuins at a glance. J. Cell Sci. 2011, 124, 833-838.

146. Aquilano, K.; Vigilanza, P.; Baldelli, S.; Pagliei, B.; Rotilio, G.; Ciriolo, M.R. Peroxisome proliferator-activated receptor $\gamma$ co-activator $1 \alpha(\mathrm{PGC}-1 \alpha)$ and sirtuin 1 (SIRT1) reside in mitochondria. Possible direct function ion mitochondrila biogenesis. J. Biol. Chem. 2010, 285, 21590-21599.

147. Nemoto, S.; Fergusson, M.M.; Finkel, T. SIRT1 functionally interacts with the metabolic regulator and transcriptional coactivator PGC-1 $\alpha$. J. Biol. Chem. 2005, 280, 16456-16460.

148. Alcendor, R.R.; Gao, S.; Zhai, P.; Zablocki, D.; Holle, E.; Yu, X.; Tian, B.; Wagner, T.; Vatner, S.F.; Sadoshima, J. Sirt1 regulates aging and resistance to oxidative stress in the heart. Circ. Res. 2007, 100, 1512-1521.

149. Hsu, C.P.; Zhai, P.; Yamamoto, T.; Maejima, Y.; Matsushima, S.; Hariharan, N.; Shao, D.; Takagi, H.; Oka, S.; Sadoshima, J. Silent information regulator 1 protects the heart from ischemia/reperfusion. Circulation 2010, 122, 2170-2182.

150. Orallo, F.; Alvarez, E.; Camina, M.; Leiro, J.M.; Gomez, E.; Fernandez, P. The possible implication of trans-Resveratrol in the cardioprotective effects of long-term moderate wine consumption. Mol. Pharmacol. 2002, 61, 294-302.

151. Biala, A.; Tauriainen, E.; Siltanen, A.; Shi, J.; Merasto, S.; Louhelainen, M.; Martonen, E.; Finckenberg, P.; Muller, D.N.; Mervaala, E. Resveratrol induces mitochondrial biogenesis and ameliorates Ang II-induced cardiac remodeling in transgenic rats harboring human renin and angiotensinogen genes. Blood Press. 2010, 19, 196-205.

152. Weitzel, J.M.; Iwen, K.A. Coordination of mitochondrial biogenesis by thyroid hormone. Mol. Cell. Endocrinol. 2011, 342, 1-7.

153. Venditti, P.; Bari, A.; di Stefano, L.; Cardone, A.; della Ragione, F.; D’Esposito, M.; di Meo, S. Involvement of PGC-1, NRF-1, and NRF-2 in metabolic response by rat liver to hormonal and environmental signals. Mol. Cell. Endocrinol. 2009, 305, 22-29.

154. Wulf, A.; Harneit, A.; Kröger, M.; Kebenko, M.; Wetzel, M.G.; Weitzel, J.M. T3-mediated expression of PGC-1 $\alpha$ via a far upstream located thyroid hormone response element. Mol. Cell. Endocrinol. 2008, 287, 90-95.

155. Villeneuve, C.L.; Guilbeau-Frugier, C.; Sicard, P.; Lairez, O.; Ordener, C.; Duparc, T.; de Paulis, D.; Couderc, B.; Spreux-Varoquaux, O.; Tortosa, F.; et al. p53-PGC-1 $\alpha$ pathway mediates oxidative mitochondrial damage and cardiomyocyte necrosis induced by monoamine oxidase-A up-regulation: Role in chronic left ventricular dysfunction in mice. Antioxid. Redox Signal. 2013, 18, 5-18.

156. Ingwall, J.S. Energy metabolism in heart failure and remodelling. Cardiovasc. Res. 2009, 81, 412-419.

157. Ardehali, H.; Sabbah, H.N.; Burke, M.A.; Sarma, S.; Liu, P.P.; Cleland, J.G.; Maggioni, A.; Fonarow, G.C.; Abel, E.D.; Campia, U.; et al. Targeting myocardial substrate metabolism in heart failure: Potential for new therapies. Eur. J. Heart Fail. 2012, 14, 120-129. 
158. Wrutniak-Cabello, C.; Carazo, A.; Casas, F.; Cabello, G. Triiodothyronine mitochondrial receptors: Import and molecular mechanisms. J. Soc. Biol. 2008, 202, 83-92.

159. Saelim, N.; Holstein, D.; Chocron, E.S.; Camacho, P.; Lechleiter, J.D. Inhibition of apoptotic potency by ligand stimulated thyroid hormone receptors located in mitochondria. Apoptosis 2007, 12, 1781-1794.

160. Saelim, N.; John, L.M.; Wu, J.; Park, J.S.; Bai, Y.; Camacho, P.; Lechleiter, J.D. Nontranscriptional modulation of intracellular $\mathrm{Ca}^{2+}$ signaling by ligand stimulated thyroid hormone receptor. J. Cell Biol. 2004, 167, 915-924.

161. Van Rooij, E.; Sutherland, L.B.; Qi, X.; Richardson, J.A.; Hill, J.; Olson, E.N. Control of stress-dependent cardiac growth and gene expression by a microRNA. Science 2007, 316, 575-579, doi:10.1126/science.1139089.

162. Barringhaus, K.G.; Zamore, P.D. MicroRNAs: Regulating a change of heart. Circulation 2009, 119, 2217-2224.

163. Divakaran, V.; Mann, D.L. The emerging role of microRNAs in cardiac remodeling and heart failure. Circ. Res. 2008, 103, 1072-1083.

164. Thum, T.; Galuppo, P.; Wolf, C.; Fiedler, J.; Kneitz, S.; van Laake, L.W.; Doevendans, P.A.; Mummery, C.L.; Borlak, J.; Haverich, A.; et al. MicroRNAs in the human heart: A clue to fetal gene reprogramming in heart failure. Circulation 2007, 116, 258-267.

165. Van Rooij, E.; Marshall, W.; Olson, E. Toward microRNA-based therapeutics for heart disease the sense in antisense. Circ. Res. 2008, 103, 919-928.

166. Van Rooij, E.; Sutherland, L.B.; Liu, N.; Williams, A.H.; McAnally, J.; Gerard, R.D.; Richardson, J.A.; Olson, E.N. A signature pattern of stress-responsive micrornas that can evoke cardiac hypertrophy and heart failure. Proc. Natl. Acad. Sci. USA 2006, 103, 18255-18260.

167. Van Rooij, E.; Sutherland, L.B.; Thatcher, J.E.; diMaio, J.M.; Naseem, R.H.; Marshall, W.S.; Hill, J.A.; Olson, E.N. Dysregulation of microRNAs after myocardial infarction reveals a role of miR-29 in cardiac fibrosis. Proc. Natl. Acad. Sci. USA 2008, 105, 13027-13032.

168. Roy, S.; Khanna, S.; Hussain, S.R.; Biswas, S.; Azad, A.; Rink, C.; Gnyawali, S.; Shilo, S.; Nuovo, G.J.; Sen, C.K. MicroRNA expression in response to murine myocardial infarction: miR-21 regulates fibroblast metalloprotease-2 via phosphatase and tensin homologue. Cardiovasc. Res. 2009, 82, 21-29.

169. Ren, X.P.; Wu, J.; Wang, X.; Sartor, M.A.; Qian, J.; Jones, K.; Nicolaou, P.; Pritchard, T.J.; Fan, G.C. MicroRNA-320 is involved in the regulation of cardiac ischemia/reperfusion injury by targeting heat-shock protein 20. Circulation 2009, 119, 2357-2366.

170. Sripada, L.; Tomar, D.; Singh, R. Mitochondria: One of the destinations of miRNAs. Mitochondrion 2012, 12, 593-599.

171. Ye, Y.; Perez-Polo, J.R.; Qian, J.; Birnbaum, Y. The role of microRNA in modulating myocardial ischemia-reperfusion injury. Physiol. Genomics 2011, 43, 534-542.

172. Aurora, A.B.; Mahmoud, A.I.; Luo, X.; Johnson, B.A.; van Rooij, E.; Matsuzaki, S.; Humphries, K.M.; Hill, J.A.; Bassel-Duby, R.; Sadek, H.A.; et al. MicroRNA-214 protects the mouse heart from ischemic injury by controlling $\mathrm{Ca}^{2+}$ overload and cell death. J. Clin. Investig.

2012, 122, 1222-1232. 
173. Wang, X.; Zhang, X.; Ren, X.P.; Chen, J.; Liu, H.; Yang, J.; Medvedovic, M.; Hu, Z.; Fan, G.C. MicroRNA494 targeting both proapoptotic and antiapoptotic proteins protects against ischemia/reperfusion-induced cardiac injury. Circulation 2010, 122, 1308-1318.

174. Li, J.; Donath, S.; Li, Y.; Qin, D.; Prabhakar, B.; Li, P. miR-30 regulates mitochondrial fission through targeting p53 and the dynamin-related protein-1 pathway. PLoS Genet. 2010, 6, e1000795.

175. Duisters, R.F.; Tijsen, A.J.; Schroen, B.; Leenders, J.J.; Lentink, V.; van der Made, I.; Herias, V.; van Leeuwen, R.E.; Schellings, M.W.; Barenbrug, P.; et al. miR-133 and miR-30 regulate connective tissue growth factor: Implications for a role of microRNAs in myocardial matrix remodeling. Circ. Res. 2009, 104, 170-178.

176. Gambacciani, C.; Kusmic, C.; Chiavacci, E.; Meghini, F.; Rizzo, M.; Mariani, L.; Pitto, L. miR-29a and miR-30c negatively regulate DNMT3a in cardiac ischemic tissues: Implications for cardiac remodelling. microRNA Diagn. Ther. 2013, 2013, 34-44.

177. Pantos, C.; Mourouzis, I.; Cokkinos, D.V. Thyroid hormone and cardiac repair/regeneration: From Prometheus myth to reality? Can. J. Physiol. Pharmacol. 2012, 90, 977-987.

178. Pfeffer, M.A.; Braunwald, E. Ventricular remodeling after myocardial infarction. Experimental observations and clinical implications. Circulation 1990, 81, 1161-1172.

179. Sigurdsson, A.; Eriksson, S.V.; Hall, C.; Kahan, T.; Swedberg, K. Early neurohormonal effects of trandolapril in patients with left ventricular dysfunction and a recent acute myocardial infarction: A double-blind, randomized, placebo-controlled multicentre study. Eur. J. Heart Fail. 2001, 3, 69-78.

(C) 2015 by the authors; licensee MDPI, Basel, Switzerland. This article is an open access article distributed under the terms and conditions of the Creative Commons Attribution license (http://creativecommons.org/licenses/by/4.0/). 